\title{
$\beta 2-1$ Fructan supplementation alters host immune responses in a manner consistent with increased exposure to microbial components: results from a double-blinded, randomised, cross-over study in healthy adults
}

\author{
Sandra T. Clarke ${ }^{1}$, Julia M. Green-Johnson ${ }^{1}$, Stephen P. J. Brooks ${ }^{2}$, D. Dan Ramdath ${ }^{3}$, Premysl Bercik ${ }^{4}$, \\ Christian Avila ${ }^{4}$, G. Douglas Inglis ${ }^{5}$, Judy Green ${ }^{2}$, L. Jay Yanke ${ }^{5}$, L. Brent Selinger ${ }^{6}$ and \\ Martin Kalmokoff ${ }^{7 *}$ \\ ${ }^{1}$ Applied Bioscience Graduate Program, Faculty of Science, University of Ontario Institute of Technology, Oshawa, ON, \\ Canada $\mathrm{L} 1 \mathrm{H} 7 \mathrm{~K} 4$ \\ ${ }^{2}$ Bureau of Nutrition Research, Health Canada, Ottawa, ON, Canada K1A OKO \\ ${ }^{3}$ Guelph Food Research Centre, Agriculture and Agri-Food Canada, Guelph, ON, Canada N1G 5C9 \\ ${ }^{4}$ McMaster University, Hamilton, ON, Canada L8S $4 L 8$ \\ ${ }^{5}$ Lethbridge Research Centre, Agriculture and Agri-Food Canada, Lethbridge, AB, Canada T1J 4B1 \\ ${ }^{6}$ University of Lethbridge, Lethbridge, AB, Canada T1K $6 T 5$ \\ ${ }^{7}$ Atlantic Food and Horticulture Research Centre, Agriculture and Agri-Food Canada, Kentville, NS, Canada B4N 1J5
}

(Submitted 12 November 2015 - Final revision received 4 February 2016 - Accepted 15 February 2016 - First published online 18 March 2016)

\section{Abstract}

B2-1 Fructans are purported to improve health by stimulating growth of colonic bifidobacteria, increasing host resistance to pathogens and stimulating the immune system. However, in healthy adults, the benefits of supplementation remain undefined. Adults (thirteen men, seventeen women) participated in a double-blinded, placebo-controlled, randomised, cross-over study consisting of two 28-d treatments separated by a 14-d washout period. Subjects' regular diets were supplemented with $\beta 2-1$ fructan or placebo (maltodextrin) at $3 \times 5 \mathrm{~g} / \mathrm{d}$. Fasting blood and 1-d faecal collections were obtained at the beginning and at the end of each phase. Blood was analysed for clinical, biochemical and immunological variables. Determinations of well-being and general health, gastrointestinal (GI) symptoms, regularity, faecal SCFA content, residual faecal $\beta 2-1$ fructans and faecal bifidobacteria content were undertaken. $\beta 2-1$ Fructan supplementation had no effect on blood lipid or cholesterol concentrations or on circulating lymphocyte and macrophage numbers, but significantly increased serum lipopolysaccharide, faecal SCFA, faecal bifidobacteria and indigestion. With respect to immune function, $\beta 2-1$ fructan supplementation increased serum IL- 4 , circulating percentages of $\mathrm{CD} 282^{+} / \mathrm{TLR}^{+}$myeloid dendritic cells and ex vivo responsiveness to a toll-like receptor 2 agonist. $\beta 2-1$ Fructans also decreased serum IL-10, but did not affect C-reactive protein or serum/faecal Ig concentrations. No differences in host well-being were associated with either treatment, although the self-reported incidence of GI symptoms and headaches increased during the $\beta 2-1$ fructan phase. Although $\beta 2-1$ fructan supplementation increased faecal bifidobacteria, this change was not directly related to any of the determined host parameters.

Key words: Prebiotics: $\beta 2-1$ Fructan: Well-being: Immunology

$\beta 2-1$ Fructans are polymers of fructose and occur naturally in many grains, vegetables and fruits ${ }^{(1,2)}$. As human digestive enzymes are unable to cleave the $\beta 2-1$ bond, these polymers pass into the colon where they are metabolised by gut bacteria $^{(3,4)} \cdot \beta 2-1$ Fructans are widely used in processed foods because of their effects on product rheology, texture and baking characteristics ${ }^{(1)}$. $\beta 2-1$ Fructans are also claimed to improve health because of their actions as prebiotics ${ }^{(4,5)}$. The potential health-promoting effects of prebiotics are thought to result from the selective growth stimulation of colonic bifidobacteria and lactobacilli ${ }^{(4)}$. Possible benefits attributed to stimulating growth of these bacteria in the colon include an enhanced ability of the host to exclude pathogens from the gut, acidification of the colon due to lactic acid production and stimulation of the host immune system ${ }^{(6,7)}$. These broadly based claims imply that healthy subjects will benefit from increased $\beta 2-1$ fructan intakes ${ }^{(8)}$.

In rodents, $\beta 2-1$ fructans elicit a variety of physiological effects including increased butyrate excretion ${ }^{(9)}$, lowered concentrations of serum lipids ${ }^{(10)}$, changes in gut nitrogen

Abbreviations: BCFA, branched-chain fatty acid; GI, gastrointestinal; GSRS, Gastrointestinal Symptom Rating Scale; LPS, lipopolysaccharide; mDC, myeloid dendritic cell; P3C, Pam3Cys; TLR, toll-like receptor

* Corresponding author: M. Kalmokoff, email martin.kalmokoff@agr.gc.ca 
cycling $^{(11)}$ and increased caecal tissue accretion ${ }^{(12)}$. Their rapid fermentation in the caecum also affects gut barrier function, resulting in increased translocation of gut bacteria, mucin sloughing and irritation of the lower gut epithelial surface ${ }^{(13,14)}$. Increased mucin sloughing has been observed in one human $\beta 2-1$ fructan study ${ }^{(15)}$, but not in a second ${ }^{(16)}$. In humans, both positive and neutral effects have been reported on both serum lipid concentrations ${ }^{(17,18)}$ and bowel movement regularity $^{(16,19,20)}$. $\beta 2-1$ Fructan supplementation has also been associated with a wide range of minor gastrointestinal (GI) complaints such as increased flatulence, bloating and diarrhoea $^{(16,21)}$

The implications of a stimulatory immune effect of $\beta 2-1$ fructans in humans are unclear ${ }^{(7)}$. Much of the supporting data have been obtained using rodent models ${ }^{(14,22,23)}$, and only a few studies have been conducted in healthy human subjects $^{(21,24)}$. For example, increased faecal IgA concentrations have been observed in feeding studies involving mice or human infants $^{(25,26)}$, but not in healthy adults ${ }^{(27)}$. Increases in certain immune cell populations and cytokine levels have been observed in the Peyer's patches of rodents fed $\beta 2-1$ fructans $^{(23,28)}$, whereas in humans increases in circulating $\mathrm{B}$ cells in combination with decreases in both intercellular adhesion molecule-1 and percentages of natural killer (NK) cells were observed ${ }^{(24)}$. In contrast, a more recent trial on healthy adults found that $\beta 2-1$ fructan supplementation had no effects on circulating Ig concentrations, immune cell subsets or on neutrophil, monocyte and NK cell activities, indicating minimal impact of $\beta 2-1$ fructans on the immune system in the absence of an immune challenge ${ }^{(21)}$.

$\beta 2-1$ Fructans may have an effect of modulating inflammation associated with various pathological conditions ${ }^{(6)}$. For example, in women with type 2 diabetes, circulating concentrations of the pro-inflammatory cytokine TNF- $\alpha$ and of lipopolysaccharide (LPS) decreased following 8 weeks of $\beta 2-1$ fructan supplementation $^{(29)}$, whereas in Crohn's disease patients feeding $\beta 2-1$ fructans increased the numbers of lamina propria dendritic cells (DC) producing IL-10 and expressing toll-like receptor (TLR) 2 and 4 and reduced disease activity as determined by the Harvey Bradshaw index, although some symptoms increased ${ }^{(30)}$.

The most consistent response to $\beta 2-1$ fructan supplementation has been increases in faecal bifidobacteria content ${ }^{(21,31)}$. However, this change in the gut microbial community has yet to be linked to a repeatable health outcome in humans that would support a defined health benefit. In this study, we report the results from a randomised, double blind, cross-over clinical trial investigating the physiological, psychological and immunological impacts of $\beta 2-1$ fructan supplementation in thirty healthy adults. The impact of $\beta 2-1$ fructan supplementation on change within the faecal microbial communities will be reported in a separate publication.

\section{Methods}

\section{Subjects}

Subjects were recruited by a newspaper advertisement. Individuals interested in participating attended a clinical orientation

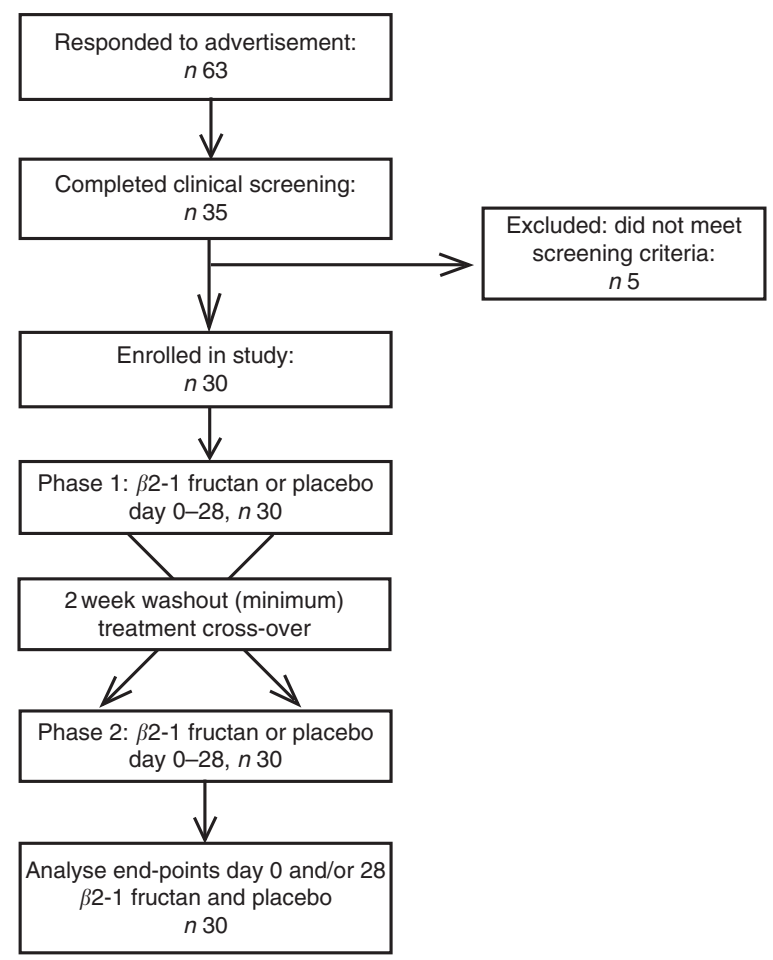

Fig. 1. Consolidated Standard of Reporting Trials diagram: progress of subjects through the trial.

and provided their written informed consent to take part in the study (Fig. 1). Subjects first completed a clinical orientation where their health status was assessed and evaluated against inclusion/exclusion criteria. Inclusion criteria were as follows: males and females, aged 18-50 years, in good general health and a BMI of $18-30 \mathrm{~kg} / \mathrm{m}^{2}$. Exclusion criteria were as follows: subjects taking medication or any health supplement, regular ingestion of high inulin-containing food products, having known GI diseases, food allergies or intolerance to any ingredients in the supplements. In all, thirty subjects (seventeen women and thirteen men) were enrolled to the study and completed both phases. This study was conducted according to the guidelines laid down in the Declaration of Helsinki, and all procedures were approved by the research ethics boards at Health Canada, McMaster University, University of Ontario Institute of Technology and by the Canadian SHIELD Ethics Review Board. The study was registered as 'Effects of fructan prebiotics on the intestinal microbiota' at www.ClinicalTrials. gov (clinical trial identifier NCT01277445). Clinical visits, enrolment, examination of the participants and generation of random treatment allocations were all carried out at Nutrasource Diagnostics Inc., Guelph, Ontario, Canada. The clinical trial was initiated on 15 November 2010 and was completed on 5 April 2011.

\section{Study design}

The present study followed a double-blind, placebo-controlled, randomised, cross-over design having two 28-d supplementation periods separated by a minimum 14-d washout period. 
Individually packaged supplements ( $5 \mathrm{~g}$ ) consisted of $\beta 2-1$ fructan (Orafti ${ }^{\circledR}$ Synergy1 (BENEO), 50:50 mixture of inulin and short-chain oligosaccharides; $15 \mathrm{~g} / \mathrm{d}$ total, $3 \times 5 \mathrm{~g}$ ingested with each meal) or placebo (maltodextrin; $15 \mathrm{~g} / \mathrm{d}$ total, $3 \times 5 \mathrm{~g}$ ingested with each meal). Investigators and subjects were blinded to the identity of the supplement or placebo, and subjects were randomised based on the order in which they were to receive either supplement (A or B). The randomisation code (Seed no. 26285) was generated using an online programme (Tufts University, www.tufts.edu/ gdallal/ random_block_size.htm). Subjects ingested either pre-packaged supplement in its entirety by dissolving the contents contained in each envelope in coffee, tea, a beverage of choice or in their food at each meal. Subjects returned any unopened supplement envelopes. Compensation occurred on day 28 of each phase.

Subjects were provided with a booklet outlining how information pertaining to the study would be collected as well as a diary to record bowel functions (the frequency of daily bowel movements) and to record self-reported adverse GI events (gas, flatulence, diarrhoea, bloating, stomach ache, heartburn and abdominal cramping) or other daily events (variations in normal activity, stress, changes in exercise patterns, medications, headaches and non-GI events such as menstrual cramps, head cold, etc.). Materials and instructions for the collection and storage of 1-d faecal samples were also provided. Subjects were instructed to fast for $12 \mathrm{~h}$ before each clinical visit, and to return unopened envelopes as well as their frozen faecal samples at the start and end of each supplement arm. Subjects completed the health-related quality-of-life short form 36 survey (HRQoL SF-36, www.sf-36.org), the General Health Questionnaire-28 (GHQ-28) ${ }^{(32)}$ and the Gastrointestinal Symptom Rating Scale (GSRS) ${ }^{(33-35)}$.

Subjects made six visits over 3 months, including at the initiation (day 1) and at the end of each phase (day 28), as well as one bi-weekly, non-clinical visit within each phase to receive a 2-week supply of envelopes and a faecal collection kit. One day before each clinical visit, subjects stored their faecal samples in their own freezer. On arrival at the clinic, faeces were stored at $-20^{\circ} \mathrm{C}$, and a $20-\mathrm{ml}$ fasting blood sample was collected. Subjects then submitted their diaries and unconsumed supplements, and at the end of each phase they completed the HRQOL, GHQ-28 and GSRS surveys. Compliance was assessed on the basis of the returned unopened supplement envelopes.

\section{Estimates of dietary $\beta 2-1$ fructan intake}

Dietary $\beta 2-1$ fructan intakes were estimated for each subject based on a semi-quantitative FFQ, completed at the end of each phase, which included the most common $\beta 2-1$ fructan-containing foods ${ }^{(36)}$. Average portion sizes were obtained from the Canadian Community Health Survey (http://www.hc-sc.gc.ca/fn-an/ surveill/nutrition/commun/cchs_focus-volet_escc-eng.php), and the midpoint of reported ranges was used to calculate consumption in $\mathrm{g} / \mathrm{d}$ dietary $\beta 2-1$ fructan $^{(36)}$.

\section{Impact of $\beta 2-1$ fructans on faecal bifidobacteria populations}

DNA was isolated from individual faecal samples as previously described $^{(37)}$. Total bacteria and bifidobacteria contents were determined by quantitative-PCR using the Agilent Brilliant Ultrafast SYBR green master mix kit (Agilent Technologies) and an Applied Biosystems ViiA real-time instrument (Applied Biosystems). Quantification of faecal eubacteria was carried out using the primer set HDA1/HDA2 (V2-3 region of the 16S rRNA gene) as previously described $^{(38)}$. For bifidobacteria, the primer set Bif582 (5'-GGTGTGAAAGYCCATCGC) and Bif815 (5'-CACATCCAG CRTCCACCG) targeting the 16S rRNA gene was used at a concentration of $5 \mu \mathrm{m}$ and an annealing temperature of $58^{\circ} \mathrm{C}$. For each sample, three technical replicates were run with copy numbers determined by comparison against a standard curve prepared from cloned 16S rRNA genes (Escherichia coli or Bifidobacterium animalis). Bifidobacteria abundance was expressed as a percentage of the total bacterial community (bifidobacteria 16S rRNA copy number/HDA1/HDA2 copy number) within each sample.

\section{Faecal analyses}

Faecal SCFA and branched-chain fatty acid (BCFA) concentrations were determined as previously described ${ }^{(39)}$. Faecal $\beta 2-1$ fructan content ( $\mathrm{g} / 100 \mathrm{~g}$ faecal dry weight) was measured using the $0-12 \%$ fructan assay procedure recommended in the Fructan Assay Kit (Megazyme).

\section{Blood analysis}

Blood analyses were carried out by LifeLabs Medical Services (Toronto, Ontario, Canada). Measurements included serum biochemistry (fasting glucose, creatinine, aspartate aminotransferase, $\gamma$-glutamyl-transferase, C-reactive protein (CRP), total globulin, albumin and total blood protein), lipid profiles (total cholesterol, LDL-cholesterol, HDL-cholesterol and TAG) and standard haematological profiles. Blood urea nitrogen was determined in serum as previously described ${ }^{(40)}$. Serum LPS concentrations were determined using the Limulus Amebocyte Lysate Assay QCL-100 (Lonza) according to the manufacturer's procedure.

\section{Cell population analysis}

Immune cell populations were determined by flow cytometry and immunofluorescence (online Supplementary Table S1). Flow cytometry was performed on a BD FACSCalibur ${ }^{\mathrm{TM}}$ flow cytometer (BD Biosciences) equipped with a blue laser $(488 \mathrm{~nm})$ and a red diode laser $(635 \mathrm{~nm})$. Data were analysed using BD FACSDIVA ${ }^{\mathrm{TM}}$ software (BD Biosciences). Blood samples were first treated with the Immunoprep ${ }^{\mathrm{TM}}$ Reagent System (Beckman Coulter) to remove erythrocytes before staining.

In a subset of six randomly selected subjects, whole blood was stimulated with $1 \mu \mathrm{g} / \mathrm{ml}$ LPS (Sigma-Aldrich) and incubated at $37^{\circ} \mathrm{C}, 5 \% \mathrm{CO}_{2}$ to investigate functional TLR responses in DC and macrophages by measuring intracellular cytokine production. Following $1 \mathrm{~h}$ incubation with LPS, $1 \mathrm{mg} / \mathrm{ml}$ Brefeldin A (Sigma-Aldrich) was added to each sample to block cytokine secretion, and samples were further incubated at $37^{\circ} \mathrm{C}$, $5 \% \mathrm{CO}_{2}$ for $2 \mathrm{~h}$. Cells were collected by centrifugation and permeabilised to allow direct intracellular staining with anti-cytokine antibodies to measure production of intracellular IL-12p70 and TNF- $\alpha$ by flow cytometry. Antibodies used for 
intracellular cytokine determinations are also listed in the online Supplementary Table S1.

\section{Cytokine profiles}

Circulating cytokines were quantified by ELISA. The following cytokines were measured in serum previously frozen at $-80^{\circ} \mathrm{C}$ : granulocyte-colony stimulating factor, granulocyte-macrophage colony stimulating factor (GM-CSF), interferon- $\gamma$ (IFN- $\gamma$ ), IL receptor antagonist, IL- $1 \beta$, IL-4, IL-6, IFN- $\gamma$-induced protein 10 , soluble CD40 ligand/TNFSF5 (R\&D Systems), IL-10, IL-12p70, TNF- $\alpha$ (BioLegend) and IL- 8 (Invitrogen). Concentrations of active and total transforming growth factor- $\beta$ were measured in plasma (R\&D Systems). All cytokines were quantified by ELISA according to the manufacturer's procedures, and ELISA plates were read at $450 \mathrm{~nm}$ using a Synergy HTTR microplate reader (BioTek).

\section{Analysis of toll-like receptor agonist-induced responses of peripheral blood cells}

An ex vivo protocol was utilised to investigate TLR responsiveness to antigens. Whole blood was collected in heparin-containing tubes at the end of each supplement phase, and was stimulated with either the TLR2 agonist Pam3Cys (P3C) (Novabiochem) or the TLR4 agonist LPS to analyse cytokine production profiles and assess alterations in TLR agonist sensitivity. Whole blood was stimulated in 5-ml polypropylene round-bottom tubes with either $1 \mu \mathrm{g} / \mathrm{ml} \mathrm{LPS} \mathrm{or} \mathrm{with} 10 \mu \mathrm{g} / \mathrm{ml} \mathrm{P3C} \mathrm{reconstituted} \mathrm{in} \mathrm{Roswell} \mathrm{Park}$ Memorial Institute (RPMI) 1640 medium. The tubes were subsequently incubated at $37^{\circ} \mathrm{C}$ in a $5 \% \mathrm{CO}_{2}$-humidified incubator for $20 \mathrm{~h}$ with an unstimulated negative control for each individual. Supernatants were collected from these samples and stored at $-80^{\circ} \mathrm{C}$ until analysis. Cytokine profiles were investigated using the BD Cytometric Bead Array Human flex set (BD Biosciences) containing IFN- $\alpha$, IL-1 $\beta$, IL-6, IL-8, IL-10, IL-12p70 and TNF- $\alpha$. Flow cytometric acquisition was performed on a BD LSRFortessa ${ }^{\mathrm{TM}}$ flow cytometer (BD Biosciences) equipped with multiple lasers (blue 488, red 640 and violet 405).

\section{Ig profiles}

Serum Ig levels were quantified with the human Ig isotyping magnetic bead panel (MILLIPLEX Map Kit; Millipore) using a Luminex 200 analyzer. Faecal IgA, IgG and IgM were quantified by ELISA (Bethyl Laboratories Inc.). Samples were prepared in phosphate-buffered saline (PBS) containing $10 \mathrm{mg} / \mathrm{ml}$ bovine serum albumin and $1 \%$ Protease Inhibitor Cocktail (SigmaAldrich). Thawed faeces samples were mixed with PBS solution at a ratio of 1:5 (w/v), incubated for $10 \mathrm{~min}$ at room temperature, homogenised using a Brinkmann Polytron PT3000 homogenizer (Kinematica) and centrifuged ( $4000 \boldsymbol{g}$ for $30 \mathrm{~min}$ at $20^{\circ} \mathrm{C}$ ). Supernatants were collected and stored at $-80^{\circ} \mathrm{C}$. ELISA plates were read at a wavelength of $450 \mathrm{~nm}$ (Infinite ${ }^{\circledR} 200$ PRO series; Tecan).

\section{Statistical analyses}

In most instances, data analyses were performed using repeated-measures ANOVA with time (day 0 and day 28) and supplement (placebo and fructan) as the repeated variables (Statistica version 12; StatSoft). In the case of peripheral blood immune cell phenotypes and SCFA (absence of day 0 values), data were also analysed by repeated-measures ANOVA but with supplement as the only repeated measure. When significant $(P<0.05)$, differences among groups were tested using a Tukey's honest significant difference (HSD) test. For some measures, there was a high proportion of individuals with values below the limit of quantification (LoQ). In these cases, the value was set to LoQ/ $2^{(41)}$ and the groups were analysed using the non-parametric Friedman's test (one-way repeatedmeasures ANOVA by ranks) followed by a Wilcoxon's matchedpairs signed-rank test to determine differences and corrected for false discovery rate. Values are reported as means with their standard errors. For ANOVA where $P>0 \cdot 05$, results are reported as non-significant. Dependent variables were assessed for normality by four methods: visual inspection of a means $v$. variance plot, inspection of the distribution of residuals, Levene's test and significance of the $\lambda$ parameter after Box-Cox transformation. If required, data were normalised by Box-Cox transformation before parametric tests.

Survey-based results (estimates of dietary $\beta 2-1$ fructan intakes, self-reported adverse events, HRQOL, SF-36, GHQ and GSRS) were also analysed using a Friedman's test with post hoc testing carried out using a Wilcoxon's matched-pairs signed-rank test corrected for false discovery rate. Associations between bifidobacteria, physiological and immune parameters (continuous variables) were assessed by Pearson's (linear) correlation analysis. When multiple pair-wise comparisons or correlations were performed, the $P$ values were corrected for false discovery rate using a web-based correction calculator (http://www.sdmproject.com); $P<0.05$ was considered to be significant.

\section{Results}

\section{Subject characteristics}

The baseline characteristics of the subjects are presented in Table 1 and online Supplementary Table S2. In total, thirty adults (thirteen male, seventeen female) completed both supplement phases. All thirty subjects had good health status before starting the trial. Compliance (number of supplements used/total given) in the placebo phase was 97.6 (SEM 0.5) \% and in the $\beta 2-1$ fructan phase 99.9 (SEM 6.9)\%. No change in cohort BMI occurred over the course of the trial. No significant differences were found in estimates of dietary $\beta 2-1$ fructan daily intakes in subjects across the cohort $(1.09 \mathrm{~g} / \mathrm{d}$ in placebo $v$. $0.96 \mathrm{~g} / \mathrm{d}$ for $\beta 2-1$ fructan phase; $P=0.15$; two-tailed $t$ test; online Supplementary Table S3).

\section{Well-being and gut symptomology}

GI symptoms and well-being were assessed using three different surveys completed during the clinical orientation (baseline) and at the end of each supplement phase. The GHQ-28 was used to assess psychiatric stress. No significant effect was associated with either supplement $(P=0 \cdot 84$; Fig. $2(\mathrm{a}))$ nor were there any significant differences in the different domains within the survey (Fig. 2(b)). Significant differences were found with the GSRS, used to assess the effect of treatment on 
Table 1. Participant characteristics*

(Mean values, standard deviations and $95 \%$ confidence intervals)

\begin{tabular}{lc}
\hline Characteristics & $n$ \\
\hline Sex & \\
Male & 13 \\
Female & 17 \\
Age (years) & \\
Mean & $28 \cdot 1$ \\
SD & $5 \cdot 1$ \\
$95 \% \mathrm{Cl}$ & $26 \cdot 2,30 \cdot 0$ \\
Height (m) & \\
Mean & $1 \cdot 69$ \\
SD & $0 \cdot 10$ \\
$95 \% \mathrm{Cl}$ & $1 \cdot 66,1 \cdot 73$ \\
Weight (kg) & $69 \cdot 8$ \\
Mean & $12 \cdot 4$ \\
SD & $65 \cdot 2,74 \cdot 4$ \\
$95 \% \mathrm{Cl}$ & \\
BMI (kg/m $\left.{ }^{2}\right)$ & $24 \cdot 2$ \\
Mean & $3 \cdot 0$ \\
SD & $23 \cdot 1,25 \cdot 4$ \\
$95 \% \mathrm{Cl}$ & \\
Systolic blood pressure (mmHg) & $121 \cdot 1$ \\
Mean & $12 \cdot 3$ \\
SD & $116 \cdot 5,125 \cdot 7$ \\
$95 \% \mathrm{Cl}$ & \\
Diastolic blood pressure (mmHg) & $77 \cdot 9$ \\
Mean & $8 \cdot 3$ \\
SD & $74 \cdot 8,81 \cdot 0$ \\
$95 \% \mathrm{Cl}$ & \\
\hline
\end{tabular}

* Data are shown for subjects who completed the study $(n 30)$.

gastrointestinal symptoms. $\beta 2-1$ Fructan consumption increased GI symptoms compared with the placebo and baseline $(P=0.04$; Fig. 3(A)). Analysis of the distinct domains of the GSRS (Fig. 3(B)) indicated that $\beta 2-1$ fructan significantly increased indigestion $(P<0.001)$ and there was a trend towards increased abdominal pain $(P=0.05)$ compared with the baseline and placebo. No significant changes were noted in quality of life as assessed using the HRQOL SF-36 questionnaire ( $P=0.63$ for the physical component and $P=0.42$ for the mental component; online Supplementary Fig. S1). $\beta 2-1$ Fructan consumption was associated with higher frequency of selfreported adverse GI events such as gas, bloating and cramping $(P<0.001)$, specifically a higher frequency of GI issues $(P=0.01)$ and headaches $(P=0.043$; Table 2$)$. No effect on the frequency of daily bowel movements was observed (placebo 1.61 (SEM 0.76) v. $\beta 2-1$ fructan 1.67 (SEM 0.70), $P=0.31$ ).

\section{Faecal bifidobacteria populations, SCFA concentrations and} residual $\beta 2-1$ fructan

$\beta 2-1$ Fructan supplementation increased the content of faecal bifidobacteria 16S rRNA genes by almost 3-fold (1.93 (SEM 0.35) v. 5.71 (sem 1.00) \%; $n$ 30; $P<0.001$; Fig. 4; online Supplementary Table S4). No correlation between the increased faecal bifidobacteria content and any of the measured parameters was found. $\beta 2-1$ Fructan supplementation significantly increased total faecal SCFA concentrations $(89.54$ (SEM 5.8) $v .81 .62$ (SEM 6.2) $\mu \mathrm{mol} / \mathrm{g}$ wet weight for placebo; $P<0.001$ ), increasing the proportion of propionate and butyrate at the expense of acetate and reducing the proportions of BCFA with the exception of
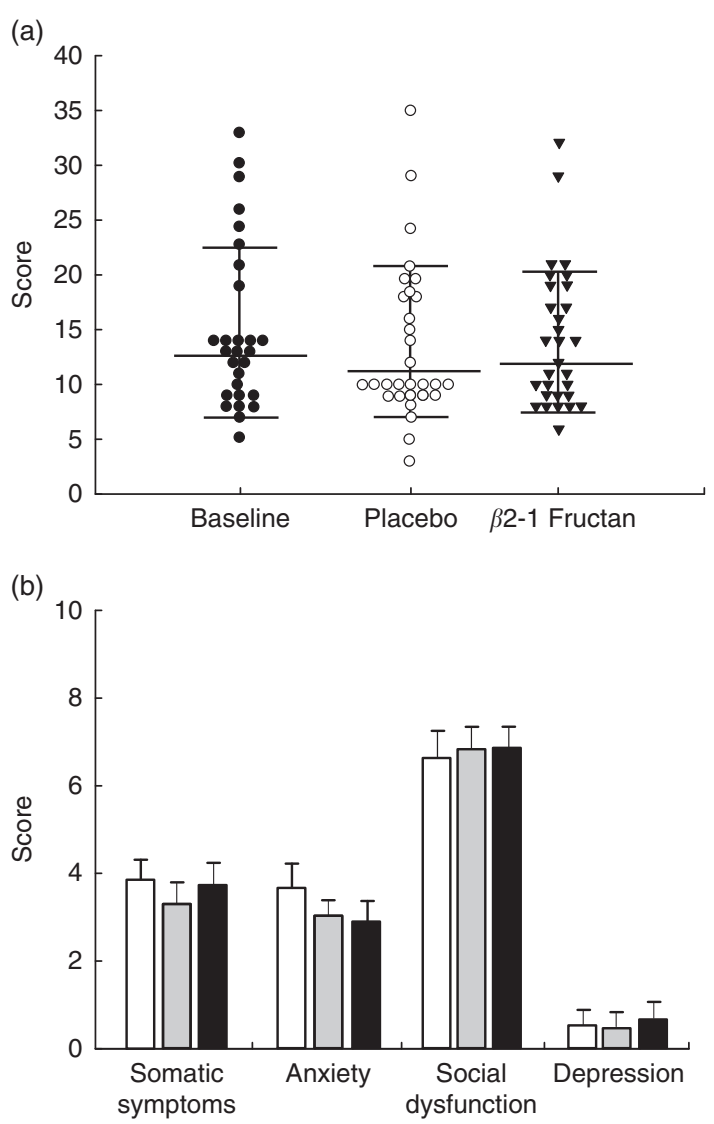

Fig. 2. (a) Assessment of emotional distress in subjects at baseline (O) and following supplementation with placebo $(\bigcirc)$ or $\beta 2-1$ fructan $(\boldsymbol{\nabla})$ based on results derived from the General Health Questionnaire-28 (GHQ-28) questionnaire. Values are means ( $n 30)$, and standard errors represented by vertical bars. The total possible scores for the GHQ-28 ranges from 0 to 84 , with higher scores indicating greater distress. No significant differences were found between baseline and either treatment $(P=0.84)$. (b) Comparison of individual domains within the GHQ-28 questionnaire, including somatic symptoms, anxiety and social dysfunction: baseline $(\square)$, placebo $(\square)$ and $\beta 2-1$ fructan ( $\square$ ). No significant differences were found in any of the four domains.

heptanoic acid (Fig. 5; online Supplementary Table S5). Average residual $\beta 2-1$ fructan content of faeces was higher following the placebo phase $(0 \cdot 10$ (SEM 0.42) v. 0.04 (SEM 0.04) g/100g dry weight for the prebiotic phase), although this difference was not significant $(P=0 \cdot 19$; one tailed $t$ test $)$.

\section{Blood biochemistry}

$\beta 2-1$ Fructan supplementation had no effect on any blood biochemistry analytes or haematological profiles (online Supplementary Table S6). As an indirect measure of bacterial translocation, serum LPS concentrations were determined (Table 3). Serum LPS concentrations were significantly higher at the end of the $\beta 2-1$ fructan phase compared with the placebo phase and day 0 of the $\beta 2-1$ fructan phase $(P=0 \cdot 03)$.

\section{Circulating immune cell populations and cytokine profiles - serum and faecal Ig concentrations}

There were no differences in $\mathrm{T}$ or $\mathrm{B}$ lymphocyte populations between phases (Table 4). However, percentages of 
(A)

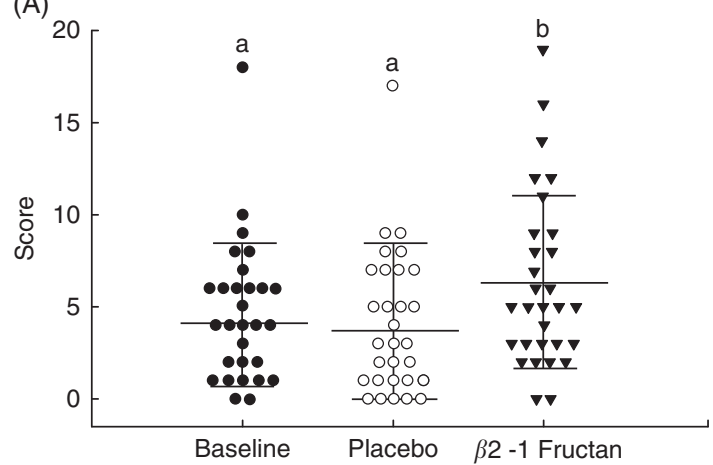

(B)

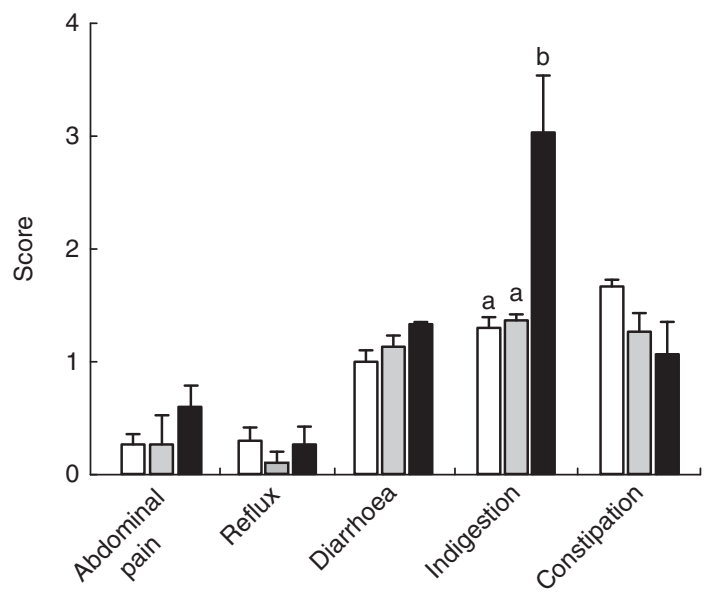

Fig. 3 . (A) Assessment of gastrointestinal symptoms in subjects at baseline $(O)$ and following supplementation with placebo $(\boldsymbol{O})$ or $\beta 2-1$ fructan $(\boldsymbol{\nabla})$ based on results derived from the Gastrointestinal Symptom Rating Scale (GSRS) questionnaire. Values are means ( $n 30$ ), and standard errors represented by vertical bars. Higher scores indicate greater symptom severity. ${ }^{a, b}$ Mean values with unlike letters were significantly different between baseline and supplements $(P=0.04)$, as determined by a Wilcoxon's matched-pairs signed-rank test. (B) Comparison of individual domains within the GSRS questionnaire, including abdominal pain, reflux, diarrhoea, indigestion and constipation: baseline $(\square)$, placebo $(\square)$ and $\beta 2-1$ fructan $(\square)$. $\beta 2-1$ Fructans significantly increased indigestion $(P<0.001)$ and there was a trend towards increased abdominal pain $(P=0.05)$.

Table 2. Self-reported adverse gastrointestinal (GI) symptoms and other adverse events in subjects receiving placebo or $\beta 2-1$ fructan $(n 30)$

\begin{tabular}{lccr}
\hline & Placebo & $\beta 2-1$ Fructan & \multicolumn{1}{c}{$P^{\star}$} \\
\hline Total Gl symptoms $\dagger$ & 18 & 44 & 0.013 \\
Headache & 15 & 35 & 0.043 \\
Total Gl symptoms and headache $\ddagger$ & 33 & 79 & $<0.001$ \\
Total symptoms§ & 44 & 89 & 0.005 \\
\hline
\end{tabular}

* Values differ significantly as determined by the Wilcoxon's matched-pairs signedrank test.

† Total Gl symptoms include abdominal cramping and pain, bloating, constipation, diarrhoea, flatulence, gas, heartburn, indigestion and reflux.

$\mp$ Includes total Gl symptoms and headache.

$\S$ All symptoms reported including Gl symptoms, non-Gl symptoms (allergies, sore throat, congestion, menstrual cramps) and headache.

$\mathrm{CD}_{282^{+}} / \mathrm{TLR}^{+}$myeloid dendritic cells $(\mathrm{mDC})(P=0.008)$ were higher following the $\beta 2-1$ fructan phase. A trend towards higher percentages of $\mathrm{CD} 284^{+} / \mathrm{TLR}^{+}$granulocytes $(P=0.05)$ and

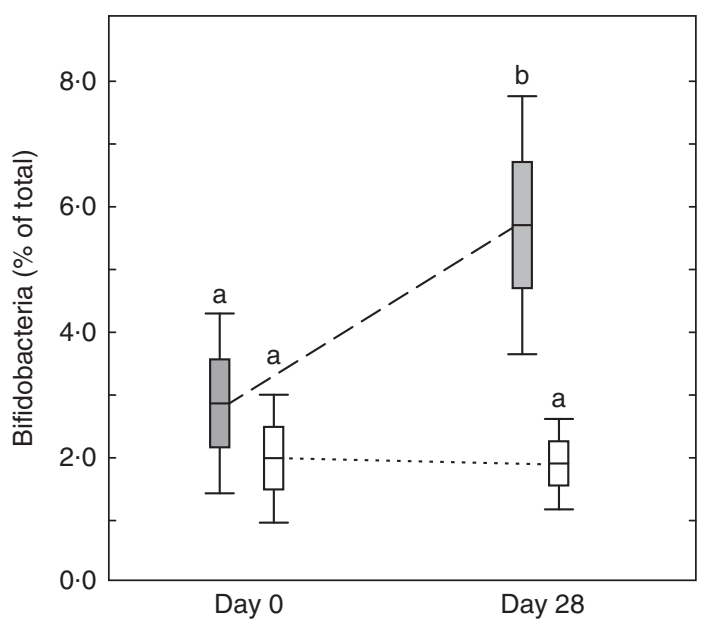

Fig. 4. Change in the abundance of faecal bifidobacteria over the duration of each supplement phase: placebo $(\square), \beta 2-1$ fructan $(\square)$. Box and whisker plot indicating the mean values and standard errors and the means $\pm 1.96 \times$ standard errors for each determination. Faecal bifidobacteria content was significantly different $(P<0.001)$. ${ }^{\mathrm{a}, \mathrm{b}}$ Mean values with unlike letters were significantly different at $P<0.05$ level as determined by Tukey's HSD. Corresponding data are available in online Supplementary Table S4.

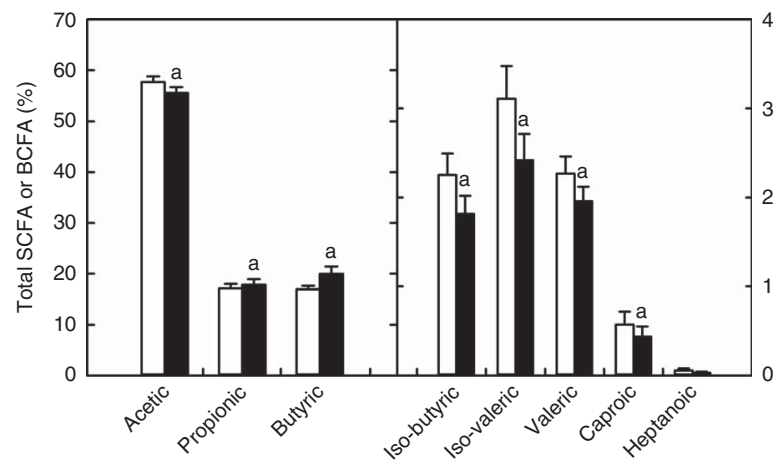

Fig. 5. Change in faecal SCFA and branched-chain fatty acid (BCFA) proportions at the end of the placebo $(\square)$ and $\beta 2-1$ fructan $(\square)$ supplement phase. Values are means ( $n 30)$, and standard errors represented by vertical bars. ${ }^{a}$ Values are expressed as a percentage of the total SCFA/BCFA content; those demonstrating a significant increase or decrease in relative proportion. Individual SCFA/BCFA proportions under both phases are available in online Supplementary Table S5.

$\mathrm{CD}^{284^{+}}$TLR $^{+}$mDC $(P=0 \cdot 06)$ was also observed. Certain serum cytokines associated with key $\mathrm{T}$ cell subsets and with pro-inflammatory and regulatory immune activities showed significant changes after $\beta 2-1$ fructan supplementation (Table 3). $\beta 2-1$ Fructan consumption lowered concentrations of regulatory cytokine IL-10 $(P<0 \cdot 001)$ but increased concentrations of T helper 2 cytokine IL-4 $(P<0.001)$ and proinflammatory cytokine GM-CSF $(P=0 \cdot 045)$.

The effects of treatment on serum and faecal Ig concentrations are shown in Table 5. Although significant differences were found in serum and faecal Ig concentrations over the course of the trial, these differences did not directly correlate with either treatment phase. The results for serum Ig concentrations were confirmed by retesting samples from six randomly selected subjects using ELISA. 
Table 3. Circulating lipopolysaccharide (LPS), cytokine and chemokine concentrations in subjects receiving placebo or $\beta 2-1$ fructan supplements (Mean values with their standard errors, $n$ 30)

\begin{tabular}{|c|c|c|c|c|c|c|c|c|c|}
\hline \multirow[b]{3}{*}{ Markers } & \multicolumn{4}{|c|}{ Placebo } & \multicolumn{4}{|c|}{$\beta 2-1$ Fructan } & \multirow[b]{3}{*}{$P$} \\
\hline & \multicolumn{2}{|c|}{ Day 0} & \multicolumn{2}{|c|}{ Day 28} & \multicolumn{2}{|c|}{ Day 0} & \multicolumn{2}{|c|}{ Day 28} & \\
\hline & Mean & SEM & Mean & SEM & Mean & SEM & Mean & SEM & \\
\hline LPS $(E U / m l)^{*}$ & $0.5^{\mathrm{a}}$ & 0.1 & $0.5^{\mathrm{a}}$ & $0 \cdot 1$ & $0.5^{\mathrm{a}}$ & 0.1 & $0.6^{b}$ & 0.1 & 0.030 \\
\hline sCD40L (ng/ml)† & $6 \cdot 6^{\mathrm{b}}$ & 4.7 & $6 \cdot 7^{\mathrm{a}, \mathrm{b}}$ & 4.9 & $6 \cdot 2^{\mathrm{a}}$ & $4 \cdot 8$ & $5 \cdot 5^{a}$ & 4.0 & 0.034 \\
\hline $\mathrm{G}-\mathrm{CSF}(\mathrm{pg} / \mathrm{ml}) \dagger$ & $12 \cdot 0^{\mathrm{b}}$ & 4.2 & $14 \cdot 6^{a, b}$ & $3 \cdot 6$ & $3 \cdot 2^{a}$ & 1.5 & $5 \cdot 8^{\mathrm{a}}$ & $2 \cdot 4$ & 0.007 \\
\hline GM-CSF $(\mathrm{pg} / \mathrm{ml}) \dagger$ & \multirow{2}{*}{\multicolumn{2}{|c|}{$<\mathrm{LOQ}^{\mathrm{a}}$}} & $238^{a}$ & 177 & $220^{\mathrm{a}}$ & 174 & $242^{\mathrm{b}}$ & 178 & 0.045 \\
\hline IFN- $\gamma(\mathrm{pg} / \mathrm{ml}) \dagger$ & & & $5 \cdot 3^{a}$ & $2 \cdot 0$ & $17 \cdot 7^{\mathrm{a}, \mathrm{b}}$ & 7.8 & $68.4^{\mathrm{b}}$ & $22 \cdot 8$ & 0.002 \\
\hline $\mathrm{IL}-1 \beta(\mathrm{pg} / \mathrm{ml}) \dagger$ & 165 & 105 & 162 & 105 & 165 & 105 & 170 & 114 & NS \\
\hline $\mathrm{IL}-1 \mathrm{Ra}(\mathrm{pg} / \mathrm{ml}) \dagger$ & 84 & 40 & 109 & 51 & 73 & 42 & 576 & 413 & NS \\
\hline $\mathrm{IL}-4(\mathrm{pg} / \mathrm{ml}) \dagger$ & $13 \cdot 0^{b, c}$ & $6 \cdot 4$ & $11 \cdot 6^{a, b}$ & $6 \cdot 3$ & $10 \cdot 4^{\mathrm{a}}$ & 5.5 & $14 \cdot 0^{c}$ & 7.3 & $<0.001$ \\
\hline IL-6 (pg/ml)† & $93^{\mathrm{b}}$ & 58 & $79^{\mathrm{a}, \mathrm{b}}$ & 49 & $47^{\mathrm{a}}$ & 31 & $83^{a, b}$ & 51 & 0.005 \\
\hline IL-8 (pg/ml)* & 18.4 & 5.0 & $23 \cdot 1$ & 8.4 & $26 \cdot 7$ & 8.3 & $30 \cdot 3$ & 9.5 & NS \\
\hline $\mathrm{IL}-10(\mathrm{pg} / \mathrm{ml}) \dagger$ & $72^{\mathrm{b}}$ & 36 & $80^{\mathrm{b}}$ & 42 & $52^{b}$ & 28 & $41^{\mathrm{a}}$ & 29 & $<0.001$ \\
\hline IL-12p70 (pg/ml)† & 217 & 153 & 201 & 139 & 155 & 118 & 208 & 162 & NS \\
\hline IP-10 (pg/ml) & 387 & 261 & 487 & 282 & 481 & 263 & 454 & 275 & 0.050 \\
\hline TNF- $a(\mathrm{pg} / \mathrm{ml}) \dagger$ & $61^{\mathrm{a}}$ & 39 & $123^{b}$ & 85 & $107^{\mathrm{a}, \mathrm{b}}$ & 83 & $124^{\mathrm{a}, \mathrm{b}}$ & 101 & 0.048 \\
\hline Total TGF- $\beta$ (ng/ml)* & 4.0 & 0.3 & 3.8 & 0.4 & 4.0 & 0.4 & 3.7 & 0.4 & NS \\
\hline Active TGF- $\beta(\mathrm{pg} / \mathrm{ml}) \dagger$ & $3 \cdot 1$ & 1.2 & 3.9 & 1.5 & 3.5 & $1 \cdot 2$ & $6 \cdot 0$ & $2 \cdot 1$ & NS \\
\hline
\end{tabular}

EU, endotoxin units; sCD40L, soluble CD40 ligand; G-CSF, granulocyte-colony stimulating factor; GM-CSF, granulocyte-macrophage colony stimulating factor; IFN, interferon; IL-1Ra, receptor antagonist; <LoQ, below limit of quantitation; IP-10, IFN- $\gamma$-induced protein 10; TGF, transforming growth factor.

* $P$ values determined by repeated-measures ANOVA. ${ }^{a, b, c}$ Mean values within a row with unlike superscript letters were significantly different as determined by Tukey's HSD

$\dagger P$ values determined by the Friedman's test. ${ }^{\text {a,b,c }}$ Mean values within a row with unlike superscript letters were significantly different as determined by Wilcoxon's matched-pairs signed-rank test.

Table 4. Peripheral blood immune cell phenotypes at the end of placebo or $\beta 2-1$ fructan phases

(Mean values with their standard errors, $n$ 30)

\begin{tabular}{|c|c|c|c|c|c|}
\hline \multirow[b]{2}{*}{ Cell phenotypes } & \multicolumn{2}{|c|}{ Placebo (day 28) } & \multicolumn{2}{|c|}{$\beta 2-1$ Fructan (day 28) } & \multirow[b]{2}{*}{$P$} \\
\hline & Mean & SEM & Mean & SEM & \\
\hline Lymphocytes $\left(\%\right.$ of cells) ${ }^{\star}$ & 34.2 & 1.7 & 34.9 & $1 \cdot 1$ & NS \\
\hline $\mathrm{CD}^{+} \mathrm{T}$ cells (\% of lymphocytes) & 74.2 & 1.2 & 73.9 & 1.2 & NS \\
\hline $\mathrm{CD}^{+}{ }^{+} \mathrm{CD} 4^{+} \mathrm{T}$ helper cells( $\%$ of lymphocytes) & 45.5 & 1.5 & $45 \cdot 6$ & 1.4 & NS \\
\hline $\mathrm{CD}^{+} \mathrm{CD}^{+}$cytotoxic $\mathrm{T}$ cells (\% of lymphocytes) & 27.5 & 1.2 & $27 \cdot 0$ & 1.2 & NS \\
\hline $\mathrm{CD}^{-} \mathrm{CD} 19^{+} \mathrm{B}$ cells (\% of lymphocytes) & $12 \cdot 6$ & 0.7 & $13 \cdot 0$ & 0.7 & NS \\
\hline $\mathrm{CD}^{+} \mathrm{CD} 16^{+} \mathrm{CD} 56^{+}$natural killer cells (\% of lymphocytes) & 12.4 & $1 \cdot 1$ & $12 \cdot 2$ & $1 \cdot 1$ & NS \\
\hline $\mathrm{CD}^{+}{ }^{+} \mathrm{CD} 4^{-} \mathrm{CD} 8^{-} \gamma \delta \mathrm{T}$ cells (\% of lymphocytes) & 3.0 & 0.3 & 2.9 & 0.3 & NS \\
\hline $\mathrm{CD}^{-} 14^{+}$monocytes (\% of leucocytes) & $7 \cdot 2$ & 0.4 & $7 \cdot 0$ & 0.3 & NS \\
\hline $\mathrm{CD}^{-} 16^{+}$neutrophils and granulocytes (\% of leucocytes) & $47 \cdot 3$ & 1.6 & $45 \cdot 3$ & 1.7 & NS \\
\hline lin1 $^{-} \mathrm{HLA}^{-D R^{+} \mathrm{CD} 123^{+} \mathrm{pDC}(\% \text { of lin1-HLA-DR }}{ }^{+}$cells $)$ & $10 \cdot 4$ & $1 \cdot 3$ & $10 \cdot 8$ & $1 \cdot 1$ & NS \\
\hline lin1 $1^{-} \mathrm{HLA}_{-} \mathrm{DR}^{+} \mathrm{CD} 11 \mathrm{c}^{+} \mathrm{mDC}\left(\%\right.$ of lin $1^{-} \mathrm{HLA}-\mathrm{DR}^{+}$cells $)$ & 23.2 & 1.3 & $22 \cdot 2$ & 1.9 & NS \\
\hline $\mathrm{CD}^{2} 6^{+} \mathrm{mDC}\left(\%\right.$ of lin $1^{-} \mathrm{HLA}^{\left.-\mathrm{DR}^{+} \text {cells }\right)}$ & 13.5 & $1 \cdot 1$ & 13.4 & $1 \cdot 2$ & NS \\
\hline $\mathrm{CD} 22^{+} / \mathrm{TLR}^{+}{ }^{+} \mathrm{mDC}\left(\%\right.$ of lin $1^{-} \mathrm{HLA}^{-} \mathrm{DR}^{+}$cells$)$ & 8.8 & 0.8 & $11 \cdot 2$ & 1.2 & 0.008 \\
\hline 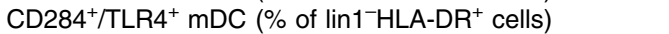 & $9 \cdot 7$ & 1.0 & 11.4 & 1.3 & 0.06 \\
\hline HLA-DR ${ }^{+}$CD $14^{+}$monocytes (\% of leucocytes) & 5.5 & 0.3 & $5 \cdot 3$ & 0.3 & NS \\
\hline $\mathrm{CD}^{282^{+} / \mathrm{TLR}^{+} \text {monocytes ( } \% \text { of leucocytes) }}{ }^{\prime}$ & 6.5 & 0.8 & $7 \cdot 8$ & 0.9 & NS \\
\hline 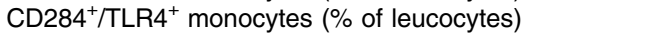 & $7 \cdot 3$ & 0.9 & 8.8 & $1 \cdot 1$ & NS \\
\hline $\mathrm{HLA}-\mathrm{DR}^{-} \mathrm{CD} 16^{+}$granulocytes (\% of leucocytes) & $28 \cdot 1$ & 1.8 & 30.2 & 1.6 & NS \\
\hline $\mathrm{CD}^{282^{+} / \mathrm{TLR}^{+}{ }^{+} \text {granulocytes ( } \% \text { of leucocytes) }}$ & 0.6 & 0.2 & 1.6 & 0.5 & NS \\
\hline 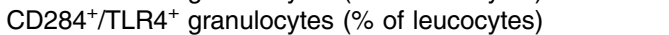 & 1.0 & 0.2 & $2 \cdot 7$ & 0.8 & 0.05 \\
\hline
\end{tabular}

pDC, plasmacytoid dendritic cells; mDC, myeloid dendritic cells.

* Determined by leucocytes differential count on a Beckman Coulter instrument.

\section{Responses of ex vivo toll-like receptor agonist stimulation}

P3C-induced IL-10 production was higher following the $\beta 2-1$ fructan phase $(P=0.016)$ but LPS-induced IL-10 production was unaffected by either supplement (Table 6). LPS (TLR4 agonist) induced higher concentrations of TNF- $\alpha$ than did stimulation with P3C (TLR2 agonist), although there was no significant effect associated with treatment phase. IFN- $\alpha$ remained below the level of detection after TLR agonist stimulation, whereas IL-12p70 was detected in only one subject after P3C stimulation in whole blood culture collected at the end of the $\beta 2-1$ fructan phase. To further examine cytokine production in response to TLR activation at the cell-specific level, intracellular cytokine accumulation was measured in $\mathrm{mDC}$ and monocytes using flow 
Table 5. Serum and faecal Ig concentrations in subjects receiving placebo or $\beta 2-1$ fructan supplements (Mean values with their standard errors, $n$ 30)

\begin{tabular}{|c|c|c|c|c|c|c|c|c|c|c|}
\hline \multirow[b]{3}{*}{ Samples } & \multirow[b]{3}{*}{ Ig class } & \multicolumn{4}{|c|}{ Placebo } & \multicolumn{4}{|c|}{$\beta 2-1$ Fructan } & \multirow[b]{3}{*}{$P$} \\
\hline & & \multicolumn{2}{|c|}{ Day $0^{*}$} & \multicolumn{2}{|c|}{ Day 28} & \multicolumn{2}{|c|}{ Day 0} & \multicolumn{2}{|c|}{ Day 28} & \\
\hline & & Mean & SEM & Mean & SEM & Mean & SEM & Mean & SEM & \\
\hline \multirow[t]{6}{*}{ Serum } & $\operatorname{lgA}(\mathrm{ng} / \mathrm{ml})$ & $698^{a}$ & 76 & $1491^{b}$ & 237 & $1390^{\mathrm{b}}$ & 234 & $912^{a}$ & 138 & 0.001 \\
\hline & $\mathrm{lgM}(\mathrm{ng} / \mathrm{ml})$ & $404^{a}$ & 33 & $821^{b}$ & 138 & $777^{\mathrm{b}}$ & 125 & $486^{a}$ & 67 & $<0.001$ \\
\hline & $\operatorname{lgG} 1(\mu \mathrm{g} / \mathrm{ml})$ & $2 \cdot 8^{\mathrm{a}}$ & 0.2 & $7 \cdot 2^{b}$ & 1.3 & $5 \cdot 2^{\mathrm{b}}$ & 0.8 & $2 \cdot 9^{\mathrm{a}}$ & 0.2 & $<0.001$ \\
\hline & lgG2 $(\mu \mathrm{g} / \mathrm{ml})$ & $1 \cdot 7^{\mathrm{a}}$ & 0.1 & $20.8^{\mathrm{b}}$ & 6.9 & $9.7^{\mathrm{b}}$ & 2.4 & $1 \cdot 6^{\mathrm{a}}$ & 0.2 & $<0.001$ \\
\hline & IgG3 $(\mu \mathrm{g} / \mathrm{ml})$ & $10 \cdot 5^{a}$ & 1.2 & $28 \cdot 2^{\mathrm{b}}$ & 3.6 & $28.7^{\mathrm{b}}$ & 2.9 & $30 \cdot 6^{\mathrm{b}}$ & 3.4 & $<0.001$ \\
\hline & IgG4 $(\mu \mathrm{g} / \mathrm{ml})$ & $0.7^{\mathrm{a}}$ & 0.1 & $2 \cdot 20^{\mathrm{b}}$ & 0.47 & $1.8^{\mathrm{b}}$ & 0.4 & $2 \cdot 2^{\mathrm{b}}$ & 0.4 & $<0.001$ \\
\hline \multirow[t]{3}{*}{ Faecal } & $\lg A(\mu \mathrm{g} / \mathrm{g})$ & $95 \cdot 1$ & $17 \cdot 6$ & $92 \cdot 2$ & $15 \cdot 1$ & 84.7 & $15 \cdot 8$ & 87.4 & $12 \cdot 1$ & NS \\
\hline & $\operatorname{lgM}(\mu \mathrm{g} / \mathrm{g})$ & $6 \cdot 0^{\mathrm{a}}$ & 2.6 & $13 \cdot 4^{\mathrm{b}}$ & 3.0 & $22.5^{\mathrm{b}}$ & $7 \cdot 0$ & $14 \cdot 1^{\mathrm{b}}$ & 4.8 & 0.02 \\
\hline & $\lg G(\mu \mathrm{g} / \mathrm{g})$ & $2 \cdot 7^{\mathrm{a}, \mathrm{b}}$ & 1.5 & $0.9^{\mathrm{a}, \mathrm{b}}$ & 0.3 & $0.7^{\mathrm{a}}$ & 0.2 & $2 \cdot 4^{\mathrm{b}}$ & 1.0 & 0.04 \\
\hline
\end{tabular}

a,b,c Mean values within a row with unlike superscript letters were significantly different $P<0.05$ level as determined by Tukey's HSD. ${ }^{*} n 29$

Table 6. Ex vivo cytokine production following stimulation of toll-like receptors in whole blood collected from subjects at the end of placebo or $\beta 2-1$ fructan phases (lipopolysaccharide (LPS) stimulation (n 30), Pam3Cys (P3C) stimulation ( $n$ 24))

(Mean values with their standard errors)

\begin{tabular}{|c|c|c|c|c|c|c|c|c|}
\hline \multirow[b]{3}{*}{ Cytokines } & \multicolumn{4}{|c|}{ LPS } & \multicolumn{4}{|c|}{ P3C } \\
\hline & \multicolumn{2}{|c|}{ Placebo (day 28) } & \multicolumn{2}{|c|}{$\beta 2-1$ Fructan (day 28) } & \multicolumn{2}{|c|}{ Placebo (day 28) } & \multicolumn{2}{|c|}{$\beta 2-1$ Fructan (day 28) } \\
\hline & Mean & SEM & Mean & SEM & Mean & SEM & Mean & SEM \\
\hline $\mathrm{IL}-1 \beta(\mathrm{ng} / \mathrm{ml})$ & $8 \cdot 2$ & $1 \cdot 1$ & $9 \cdot 2$ & 1.6 & 0.3 & 0.1 & 0.5 & $0 \cdot 1$ \\
\hline IL-6 (ng/ml) & 34.4 & 14.4 & $36 \cdot 6$ & $1 \cdot 7$ & 8.5 & 0.9 & 11.5 & 1.9 \\
\hline IL-8 (ng/ml) & $64 \cdot 8$ & 1.9 & $72 \cdot 7$ & $2 \cdot 3$ & 57 & $3 \cdot 2$ & $60 \cdot 7$ & 4.9 \\
\hline $\mathrm{IL}-10(\mathrm{pg} / \mathrm{ml})$ & 2044 & 147 & 2001 & 188 & 16 & $7 \cdot 0$ & $52 \cdot 0^{\star}$ & $19 \cdot 0$ \\
\hline TNF- $a(\mathrm{ng} / \mathrm{ml})$ & $2 \cdot 7$ & 0.3 & 3.0 & 0.3 & 0.2 & 0.0 & 0.2 & 0.0 \\
\hline
\end{tabular}

* Significantly different from the corresponding placebo group $(P=0.016)$ as determined by a Wilcoxon's matched-pairs signed-rank test.

cytometry following LPS stimulation of whole blood. Intracellular production of TNF- $\alpha$ and IL-12p70 in mDC and monocytes was measured in a subgroup of six subjects at phase end points. Although stimulation with LPS-induced TNF- $\alpha$ production in $\mathrm{mDC}$ and monocytes, no differences were found between treatments $(P=0.94)$. Intracellular IL-12p70 concentrations following stimulation were minimal (data not shown).

\section{Discussion}

$\beta 2-1$ Fructans are widely claimed to be health promoting, although there is little evidence to support this, particularly regarding their use in healthy subjects. In order to identify potential health benefits, we investigated their impact on a wide range of factors relating to the psychological, physiological and immunological status of healthy adults. We selected a commercially available product (Orafti ${ }^{\circledR}$ Synergy1) at an intake level recommended by the manufacturer. Supplementation at $15 \mathrm{~g} / \mathrm{d}$ resulted in intakes well above estimates of daily dietary intakes for North Americans $(1-4 \mathrm{~g} / \mathrm{d})^{(2)}$. Nevertheless, the material was completely fermented, suggesting that the colonic fermentation capacity was not exceeded. $\beta 2-1$ Fructan supplementation significantly increased the content of faecal bifidobacteria across the cohort, in agreement with previous findings ${ }^{(21,30)}$. Under the current definition for prebiotics, any potential health claim would require that this change in the gut microbiota be causally linked with a measurable and consistent response that could reasonably be considered to represent an improvement in health. An association would be considered supportive evidence $^{(8)}$.

The intakes of the present study did, however, suggest that $15 \mathrm{~g} / \mathrm{d}$ exceeds the average human tolerance for this material, as indigestion was significantly higher and there was a trend towards increases in other minor GI complaints. Although the results from the GSRS survey are retrospective, they were consistent with the increased incidence of GI complaints based on the analysis of the daily diaries. Similar complaints have been reported in other trials involving healthy subjects with $\beta 2-1$ fructan supplementation at $20 \mathrm{~g} / \mathrm{d}$ for $21 \mathrm{~d}^{(19)}, 8 \mathrm{~g} / \mathrm{d}$ for 4 weeks $^{(21)}$ and $5-20 \mathrm{~g} / \mathrm{d}$ for 2 weeks $^{(42)}$. In contrast to previous studies involving $\beta 2-1$ fructan supplementation $(25-30 \mathrm{~g} / \mathrm{d}$ for 2 weeks $^{(16)}, 13 \mathrm{~g} / \mathrm{d}$ for 3 weeks $^{(20)}$ and $8 \mathrm{~g} / \mathrm{d}$ for 4 weeks $^{(21)}$ ), we found no difference in regularity under either supplement. An unusual finding was the association of $\beta 2-1$ fructan with an increased incidence of headaches. However, gut health and overall host well-being are connected through the gut-brain axis $^{(43)}$. The impact of supplementation on perceptions of well-being and overall health represents an important but often ignored dimension. Changes in host well-being are used to clinically assess treatment efficacy in various disease states, and 
the relationship between GI health and sense of well-being is well documented $^{(44)}$. Note that, despite the minor complaints associated with $\beta 2-1$ fructans, we found no significant changes in the subject's general sense of well-being or perceptions of overall health between the $\beta 2-1$ fructan or placebo treatment phases.

$\beta 2-1$ Fructan supplementation moderately, although significantly, altered total faecal SCFA and BCFA concentrations. We found that the proportions of propionate and butyrate tended to increase at the expense of acetate, whereas others have reported increases in acetate at the expense of butyrate ${ }^{(16)}$ or no changes at all ${ }^{(19)}$. Increased SCFA concentrations occur in response to increased dietary fibre, and this effect is not specific to $\beta 2-1$ fructans. The proportions of most BCFA also moderately decreased in response to $\beta 2-1$ fructan supplementation. BCFA are formed during the fermentation of branched-chain amino acids and represent a marker for protein fermentation in the gut $^{(45)}$. The reduction in gut protein fermentation is consistent with a previous study ${ }^{(46)}$, and likely results from a shift in the balance of available gut peptidyl nitrogen sources towards microbial growth at the expense of energy production (i.e. protein fermentation) due to very rapid fermentation in the proximal colon. This effect is also not likely specific to $\beta 2-1$ fructans, and can be expected to occur with other soluble rapidly fermented polymers. Finally, as in previous studies involving healthy adults $^{(47)}$, we found that $\beta 2-1$ fructan supplementation had no effect on blood lipid or cholesterol concentrations.

Changes in Ig concentrations and isotype profiles can serve as a marker for alterations to host adaptive immune $\operatorname{activity}^{(48,49)}$. For example, in formula-fed infants, $\beta 2-1$ fructans appear to increase secretory IgA concentrations ${ }^{(50)}$. In common with a previous study in healthy adults ${ }^{(21)}$, we found no association between $\beta 2-1$ fructan treatment and Ig concentrations or isotype profiles, although we did observe considerable variation in both serum and faecal Ig concentrations over the duration of the trial. However, serum Ig concentrations are subject not only to short-term periodic fluctuations ${ }^{(51)}$ but also vary with sex, ethnicity, age and changes in season ${ }^{(48,52,53)} \cdot \beta 2-1$ Fructan-associated increases in serum or faecal IgA have been observed in infants following vaccination ${ }^{(26,54,55)}$, and increases in serum antibody titers against a seasonal flu vaccine were observed in healthy middle-aged adults ${ }^{(56)}$. As the present study was carried out in adults under resting conditions, it remains possible that differences might become apparent following an immune challenge. Without stimulating the subject's immune system by vaccination to induce an adaptive immune response, we were limited to measuring changes in total Ig concentrations. However, it is clear that the observed changes in $\mathrm{Ig}$ concentrations of healthy adults were driven by more complex factors than diet alone.

$\beta 2-1$ Fructan supplementation has been reported to affect other immune parameters in individuals potentially having compromised health. For example, increases in peripheral $\mathrm{T}$ cell subsets have been observed in elderly adults supplemented with $\beta 2-1$ fructans $^{(57)}$ and in Crohn's disease patients, where increases in the percentages of TLR2 ${ }^{+}$and TLR $4^{+}$DC producing IL-10 were observed ${ }^{(30)}$. In contrast, others have reported no changes in circulating immune cell populations in healthy adults supplemented with $\beta 2-1$ fructans ${ }^{(21)}$. Our findings regarding immune cell populations were consistent with the latter study, despite supplementing nearly twice the amount of $\beta 2-1$ fructan $(8 v .15 \mathrm{~g} / \mathrm{d})$. However, in common with the study carried out with Crohn's patients, we did observe increases in subpopulations of immune cells expressing TLR 2 and 4. Innate immune cells serve as sentinels and are highly sensitive to the presence of microbial components, which are sensed through pattern recognition receptors such as TLR2 and TLR $4^{(58,59)}$. Specifically, CD $282^{+} /$TLR2 $^{+}$mDC subpopulations were significantly increased, and an upward trend in both CD $284^{+} /$TLR $^{+}{ }^{+}$granulocytes and CD $284^{+} / \mathrm{TLR}^{+}$mDC was also observed at the end of the $\beta 2-1$ fructan phase. Changes in circulating cytokine profiles provide insight into the type of immune activity, and we observed that $\beta 2-1$ fructan supplementation was associated with lower concentrations of the regulatory cytokine IL-10, but increased concentrations of pro-inflammatory cytokine GM-CSF and of the T helper 2 cytokine IL-4. Changes in circulating cytokine profiles, in combination with increases in percentages of immune cells expressing TLR, are suggestive of encounters of the immune system with pro-inflammatory stimuli. The third approach we used to assess the response of circulating innate immune cells to microbial-derived stimuli was TLR stimulation assays ${ }^{(60,61)}$, which provided both a sensitive measure of changes in host innate immunity ${ }^{(62)}$ and insight into the ability of the host to respond to infection ${ }^{(63,64)}$. A significantly higher concentration of IL-10 induced by the TLR2 agonist P3C was associated with the $\beta 2-1$ fructan phase. Again, an increased sensitivity towards microbial-derived TLR agonists was consistent with the observed increase in $\mathrm{TLR}^{+}$subpopulations.

Although other properties of $\beta 2-1$ fructans, such as direct TLR stimulation of intestinal epithelial cells, could possibly contribute to these immunological effects ${ }^{(65)}$, our data suggest otherwise. First, serum LPS concentrations were significantly higher following the $\beta 2-1$ fructan phase. Circulating LPS is commonly used as an indirect index of gut permeability ${ }^{(66,67)}$. Second, increased translocation of gut bacteria has been previously observed in studies in rats fed diets containing $\beta 2-1$ fructans - this appears to result from irritation and damage to the gut due to the very rapid fermentation of these substrates in the caecum ${ }^{(13,14)}$. Increased TLR expression and heightened sensitivity to TLR agonists coupled with changes in circulating cytokine concentrations in combination with higher serum LPS concentrations all point towards an increase in microbial translocation during the $\beta 2-1$ fructan supplementation phase. Despite our evidence for increased translocation, we found no significant supplement phase-related change in serum CRP, indicating that alterations to gut barrier function were of non-acute nature.

In conclusion, supplementing healthy adults with $\beta 2-1$ fructan had no effect on perceptions of health or well-being. However, in common with previous studies, minor selfreported GI events were identified, as well as an association with an increased incidence of headaches. More importantly, $\beta 2-1$ fructans were found to affect host immune activity, altering circulating regulatory and pro-inflammatory cytokine 
concentrations, increasing the proportions of immune cells expressing TLR2 and 4 and influencing TLR2 agonist responsiveness in an ex vivo whole blood stimulation assay. These changes were consistent with modulation of the innate immune system resulting from increased contact with microbial-derived stimuli, as also mirrored by higher concentrations of serum LPS. Often, the purported immune-stimulating properties of $\beta 2-1$ fructans are claimed as beneficial. However, chronic stimulation of the immune system by intestinal luminal contents has also been linked to several intestinal and extra-intestinal disorders including metabolic disease ${ }^{(67)}$. Moreover, although the immunological effects observed in our study can only be described as moderate, this might not be the case in individuals ingesting these supplements over a longer period or in those having pre-existing conditions ${ }^{(68)}$. Although supplementation with $\beta 2-1$ fructans did increase the content of faecal bifidobacteria, we found no direct relationship between this change and any of the parameters measured across the study, nor could we link this change with a host response, which could reasonably be considered to represent an improvement in health. Our study involved only thirty healthy adults, and, although similar to the number of subjects used in previous controlled cross-over studies (eleven to fifteen subjects) $)^{(16,19,20)}$ and parallel studies (eighteen to twenty-two subjects) ${ }^{(21,24)}$, there remains the possibility that additional effects associated with $\beta 2-1$ fructan prebiotics may be identified in future studies examining larger cohorts.

\section{Acknowledgements}

The authors thank Emily Chomyshyn (Health Canada) and Fernando Matias (Health Canada) for their excellent technical assistance throughout the study.

This study was a project undertaken by the gut health group of the Advanced Food and Materials Network, and was supported with funding from Agriculture and Agri-Food Canada (RPBI no. 1501, M. K., G. D. I., L. J. Y.), Health Canada (S. P. J. B.), General Mills (L. B. S., M. K.), Alberta Innovates Bio Solutions (G. D. I.), the Advanced Food and Materials Network (L. B. S., M. K.) and National Science and Engineering Research Council (J. M. G.-J.).

Researchers of this group were involved in the original conception of the project (J. M. G.-J., D. D. R., P. B., G. D. I., L. J. Y., L. B. S., S. P. J. B., M. K.). D. D. R. and J. G. organised and supervised the clinical trial. C. A. and P. B. analysed and interpreted the survey-based data. S. T. C. and J. G. conducted the immunological analyses. S. T. C. and S. P. J. B. undertook and provided the statistical analyses. S. T. C., J. M. G.-J. and M. K. prepared the first draft of the manuscript. All additional authors (S. P. J. B., D. D. R., P. B., C. A., G. D. I., J. G., L. J. Y. and L. B. S.) contributed to the final content. M. K., L. B. S., J. M. G.-J. and G. D. I. receive research support from General Mills Inc. and Alberta Innovates Bio Solutions.

All other authors have no conflicts of interest to declare.

\section{Supplementary material}

For supplementary material/s referred to in this article, please visit http://dx.doi.org/doi:10.1017/S0007114516000908

\section{References}

1. Singh RS \& Singh RP (2010) Production of fructooligosaccharides from inulin by endoinulinases and their prebiotic potential. Food Technol Biotechnol 48, 435.

2. Coussement PA (1999) Inulin and oligofructose: safe intakes and legal status. J Nutr 129, 1412S-1417S.

3. Bouhnik Y, Raskine L, Simoneau G, et al. (2004) The capacity of nondigestible carbohydrates to stimulate fecal bifidobacteria in healthy humans: a double-blind, randomized, placebo-controlled, parallel-group, dose-response relation study. Am J Clin Nutr 80, 1658-1664.

4. Gibson GR \& Roberfroid MB (1995) Dietary modulation of the human colonic microbiota: introducing the concept of prebiotics. J Nutr 125, 1401-1412.

5. Schaafsma G \& Slavin JL (2015) Significance of inulin fructans in the human diet. Compr Rev Food Sci Food Safety 14, 37-47.

6. Looijer-van Langen MA \& Dieleman LA (2009) Prebiotics in chronic intestinal inflammation. Inflamm Bowel Dis 15, 454-462.

7. Lomax AR \& Calder PC (2009) Prebiotics, immune function, infection and inflammation: a review of the evidence. Br J Nutr 101, 633-658.

8. Brooks SP \& Kalmokoff ML (2012) Prebiotics and probiotics: some thoughts on demonstration of efficacy within the regulatory sphere. JAOAC Int $\mathbf{9 5}, 2-4$.

9. Le Blay G, Michel C, Blottiere HM, et al. (1999) Prolonged intake of fructo-oligosaccharides induces a short-term elevation of lactic acid-producing bacteria and a persistent increase in cecal butyrate in rats. J Nutr 129, 2231-2235.

10. Kok NN, Taper HS \& Delzenne NM (1998) Oligofructose modulates lipid metabolism alterations induced by a fat-rich diet in rats. J Appl Toxicol 18, 47-53.

11. Younes H, Garleb K, Behr S, et al. (1995) Fermentable fibers or oligosaccharides reduce urinary nitrogen excretion by increasing urea disposal in the rat cecum. J Nutr $\mathbf{1 2 5}$, 1010-1016.

12. Campbell JM, Fahey GC Jr \& Wolf BW (1997) Selected indigestible oligosaccharides affect large bowel mass, cecal and fecal short-chain fatty acids, $\mathrm{pH}$ and microflora in rats. $J$ Nutr 127, 130-136.

13. Ten Bruggencate SJ, Bovee-Oudenhoven IM, Lettink-Wissink ML, et al. (2004) Dietary fructo-oligosaccharides and inulin decrease resistance of rats to salmonella: protective role of calcium. Gut $\mathbf{5 3}$, $530-535$.

14. Ten Bruggencate SJ, Bovee-Oudenhoven IM, Lettink-Wissink ML, et al. (2005) Dietary fructooligosaccharides increase intestinal permeability in rats. J Nutr 135, 837-842.

15. Ten Bruggencate SJ, Bovee-Oudenhoven IM, Lettink-Wissink ML, et al. (2006) Dietary fructooligosaccharides affect intestinal barrier function in healthy men. J Nutr 136, 70-74.

16. Scholtens PA, Alles MS, Willemsen LE, et al. (2006) Dietary fructo-oligosaccharides in healthy adults do not negatively affect faecal cytotoxicity: a randomised, double-blind, placebo-controlled crossover trial. Br J Nutr 95, 1143-1149.

17. Davidson MH, Maki KC, Synecki C, et al. (1998) Effects of dietary inulin on serum lipids in men and women with hypercholesterolemia. Nutr Res 18, 503-517.

18. Wong JM, Kendall CW, de Souza R, et al. (2010) The effect on the blood lipid profile of soy foods combined with a prebiotic: a randomized controlled trial. Metabolism 59, 1331-1340.

19. Slavin J \& Feirtag J (2011) Chicory inulin does not increase stool weight or speed up intestinal transit time in healthy male subjects. Food Funct 2, 72-77.

20. Dahl WJ, Whiting SJ, Isaac TM, et al. (2005) Effects of thickened beverages fortified with inulin on beverage acceptance, gastrointestinal function, and bone resorption in institutionalized adults. Nutrition 21, 308-311. 
21. Lomax AR, Cheung LV, Tuohy KM, et al. (2012) beta2-1 Fructans have a bifidogenic effect in healthy middle-aged human subjects but do not alter immune responses examined in the absence of an in vivo immune challenge: results from a randomised controlled trial. Br J Nutr $\mathbf{1 0 8}$, 1818-1828.

22. Bovee-Oudenhoven IM, Ten Bruggencate SJ, Lettink-Wissink ML, et al. (2003) Dietary fructo-oligosaccharides and lactulose inhibit intestinal colonisation but stimulate translocation of salmonella in rats. Gut 52, 1572-1578.

23. Ryz NR, Meddings JB \& Taylor CG (2009) Long-chain inulin increases dendritic cells in the Peyer's patches and increases ex vivo cytokine secretion in the spleen and mesenteric lymph nodes of growing female rats, independent of zinc status. Br J Nutr 101, 1653-1663.

24. Seidel C, Boehm V, Vogelsang H, et al. (2007) Influence of prebiotics and antioxidants in bread on the immune system, antioxidative status and antioxidative capacity in male smokers and non-smokers. Br J Nutr 97, 349-356.

25. Nakamura Y, Nosaka S, Suzuki M, et al. (2004) Dietary fructooligosaccharides up-regulate immunoglobulin A response and polymeric immunoglobulin receptor expression in intestines of infant mice. Clin Exp Immunol 137, 52-58.

26. Scholtens PA, Alliet P, Raes M, et al. (2008) Fecal secretory immunoglobulin A is increased in healthy infants who receive a formula with short-chain galacto-oligosaccharides and longchain fructo-oligosaccharides. J Nutr 138, 1141-1147.

27. Ramnani P, Costabile A, Bustillo AG, et al. (2015) A randomised, double- blind, cross-over study investigating the prebiotic effect of agave fructans in healthy human subjects. J Nutr Sci $\mathbf{4}$, e10.

28. Roller M, Rechkemmer G \& Watzl B (2004) Prebiotic inulin enriched with oligofructose in combination with the probiotics Lactobacillus rhamnosus and Bifidobacterium lactis modulates intestinal immune functions in rats. J Nutr $\mathbf{1 3 4}$, 153-156.

29. Dehghan P, Gargari BP, Jafar-Abadi MA, et al. (2014) Inulin controls inflammation and metabolic endotoxemia in women with type 2 diabetes mellitus: a randomized-controlled clinical trial. Int J Food Sci Nutr 65, 117-123.

30. Lindsay JO, Whelan K, Stagg AJ, et al. (2006) Clinical, microbiological, and immunological effects of fructooligosaccharide in patients with Crohn's disease. Gut 55, 348-355.

31. Bouhnik Y, Raskine L, Simoneau G, et al. (2006) The capacity of short-chain fructo-oligosaccharides to stimulate faecal bifidobacteria: a dose-response relationship study in healthy humans. Nutr J $\mathbf{5}, 8$.

32. Goldberg D (1978) Manual of the General Health Questionnaire. Windsor: NFER-NELSON Publishing Company Ltd.

33. Revicki DA, Wood M, Wiklund I, et al. (1998) Reliability and validity of the Gastrointestinal Symptom Rating Scale in patients with gastroesophageal reflux disease. Qual Life Res 7, $75-83$.

34. Svedlund J, Sjodin I \& Dotevall G (1988) GSRS - a clinical rating scale for gastrointestinal symptoms in patients with irritable bowel syndrome and peptic ulcer disease. Dig Dis Sci 33, 129-134.

35. Kulich KR, Madisch A, Pacini F, et al. (2008) Reliability and validity of the Gastrointestinal Symptom Rating Scale (GSRS) and Quality of Life in Reflux and Dyspepsia (QOLRAD) questionnaire in dyspepsia: a six-country study. Health Qual Life Outcomes 6, 12

36. Moshfegh AJ, Friday JE, Goldman JP, et al. (1999) Presence of inulin and oligofructose in the diets of Americans. J Nutr $\mathbf{1 2 9}$, 1407S-1411S
37. Brooks SP, McAllister M, Sandoz M, et al. (2003) Cultureindependent phylogenetic analysis of the faecal flora of the rat. Can J Microbiol 49, 589-601.

38. Abnous K, Brooks SP, Kwan J, et al. (2009) Diets enriched in oat bran or wheat bran temporally and differentially alter the composition of the fecal community of rats. J Nutr 139, 2024-2031.

39. Scheppach WM, Fabian CE \& Kasper HW (1987) Fecal short-chain fatty acid (SCFA) analysis by capillary gas-liquid chromatography. Am J Clin Nutr 46, 641-646.

40. Kalmokoff M, Zwicker B, O'Hara M, et al. (2013) Temporal change in the gut community of rats fed high amylose corn starch is driven by endogenous urea rather than strictly on carbohydrate availability. J Appl Microbiol 114, 1516-1528.

41. Armbruster DA, Tillman MD \& Hubbs LM (1994) Limit of detection (LQD)/limit of quantitation (LOQ): comparison of the empirical and the statistical methods exemplified with GC-MS assays of abused drugs. Clin Chem 40, 1233-1238.

42. Bruhwyler J, Carreer F, Demanet E, et al. (2009) Digestive tolerance of inulin-type fructans: a double-blind, placebocontrolled, cross-over, dose-ranging, randomized study in healthy volunteers. Int J Food Sci Nutr 60, 165-175.

43. Collins SM \& Bercik P (2009) The relationship between intestinal microbiota and the central nervous system in normal gastrointestinal function and disease. Gastroenterology $\mathbf{1 3 6}$, 2003-2014

44. De Palma G, Collins SM, Bercik P, et al. (2014) The microbiota-gut-brain axis in gastrointestinal disorders: stressed bugs, stressed brain or both? J Physiol 592, 2989-2997.

45. Cummings JH \& Macfarlane GT (1991) The control and consequences of bacterial fermentation in the human colon. J Appl Bacteriol 70, 443-459.

46. Geboes KP, De Hertogh G, De Preter V, et al. (2006) The influence of inulin on the absorption of nitrogen and the production of metabolites of protein fermentation in the colon. Br J Nutr 96, 1078-1086.

47. Pedersen A, Sandstrom B \& Van Amelsvoort JM (1997) The effect of ingestion of inulin on blood lipids and gastrointestinal symptoms in healthy females. Br J Nutr 78, 215-222.

48. Cassidy JT, Nordby GL \& Dodge HJ (1974) Biologic variation of human serum immunoglobulin concentrations: sex-age specific effects. J Chronic Dis 27, 507-516.

49. Albers R, Antoine JM, Bourdet-Sicard R, et al. (2005) Markers to measure immunomodulation in human nutrition intervention studies. Br J Nutr 94, 452-481.

50. Bakker-Zierikzee AM, Tol EA, Kroes H, et al. (2006) Faecal SIgA secretion in infants fed on pre- or probiotic infant formula. Pediatr Allergy Immunol 17, 134-140.

51. Veys EM, Wieme RJ, Van Egmond J, et al. (1977) Short term variation of human immunoglobulin levels with an estimation of the day to day physiological variability. Clin Chim Acta $\mathbf{7 5}$, $275-285$.

52. Nordby GL \& Cassidy JT (1983) Seasonal effect on the variability of summer immunoglobulin levels. Hum Biol $\mathbf{5 5}$, 797-809.

53. Maddison SE, Stewart CC, Farshy CE, et al. (1975) The relationship of race, sex, and age to concentrations of serum immunoglobulins expressed in international units in healthy adults in the USA. Bull World Health Organ 52, 179-185.

54. Firmansyah A, Pramita G, Carrie Fassler A, et al. (2001) Improved humoral immune response to measles vaccine in infants receiving infant cereal with fructo-oligosaccharides. J Pediatr Gastroenterol Nutr 31, A521.

55. Saavedra JM \& Tschernia A (2002) Human studies with probiotics and prebiotics: clinical implications. Br J Nutr 87, Suppl. 2, S241-246. 
56. Lomax AR, Cheung LV, Noakes PS, et al. (2015) Inulin-type beta2-1 fructans have some effect on the antibody response to seasonal influenza vaccination in healthy middleaged humans. Front Immunol 6, 490.

57. Guigoz Y, Rochat F, Perruisseau-Carrier G, et al. (2002) Effects of oligosaccharide on the faecal flora and non-specific immune system in elderly people. Nutr Res 22, 13-25.

58. Medzhitov R, Preston-Hurlburt P \& Janeway CA Jr (1997) A human homologue of the Drosophila toll protein signals activation of adaptive immunity. Nature 388, 394-397.

59. Yang RB, Mark MR, Gray A, et al. (1998) Toll-like receptor-2 mediates lipopolysaccharide-induced cellular signalling. Nature 395, 284-288.

60. Ida JA, Shrestha N, Desai S, et al. (2006) A whole blood assay to assess peripheral blood dendritic cell function in response to toll-like receptor stimulation. J Immunol Methods 310, 86-99.

61. Della Bella S, Giannelli S, Taddeo A, et al. (2008) Application of six-color flow cytometry for the assessment of dendritic cell responses in whole blood assays. J Immunol Methods 339 , 153-164.
62. Blimkie D, Fortuno ES 3rd, Yan H, et al. (2011) Variables to be controlled in the assessment of blood innate immune responses to toll-like receptor stimulation. J Immunol Methods 366, 89-99.

63. Turvey SE \& Hawn TR (2006) Towards subtlety: understanding the role of toll-like receptor signaling in susceptibility to human infections. Clin Immunol 120, 1-9.

64. Barreiro LB, Ben-Ali M, Quach H, et al. (2009) Evolutionary dynamics of human toll-like receptors and their different contributions to host defense. PLoS Genet 5, e1000562.

65. Vogt L, Ramasamy U, Meyer D, et al. (2013) Immune modulation by different types of beta2-1-fructans is toll-like receptor dependent. PLOS ONE 8, e68367.

66. Bala S, Marcos M, Gattu A, et al. (2014) Acute binge drinking increases serum endotoxin and bacterial DNA levels in healthy individuals. PLOS ONE 9, e96864.

67. Bischoff SC, Barbara G, Buurman W, et al. (2014) Intestinal permeability - a new target for disease prevention and therapy. BMC Gastroenterol 14, 189.

68. Gibson PR \& Shepherd SJ (2010) Evidence-based dietary management of functional gastrointestinal symptoms: the FODMAP approach. J Gastroenterol Hepatol 25, 252-258. 